\title{
Correction to: Health Transformation in Saudi Arabia via Connected Health Technologies
}

\author{
Hebah ElGibreen
}

Correction to:

Chapter 10 in: P. Murthy, A. Ansehl (eds.), Technology and Global Public Health, https://doi.org/10.1007/978-3-030-46355-7_10

The chapter was inadvertently published with middle name included in the author's name as "Hebah Abdul Aziz ElGibreen" instead of "Hebah ElGibreen".

The author's name has been corrected by removing the middle name "Abdul Aziz" in "Hebah Abdul Aziz ElGibreen". The name has been updated as "Hebah ElGibreen". 